\title{
MORTALITY IN CHILDHOOD-ONSET TYPE 1 DIABETES
}

\author{
Elitsa Hadzhieva ${ }^{1}$, Mila Boyadzhieva ${ }^{1}$, Violeta Iotova ${ }^{2}$, Sonya Galcheva ${ }^{2}$, Kaloyan Tsochev ${ }^{2}$, \\ Tatiana Chalykova ${ }^{3}$, Yoto Yotov ${ }^{3}$, Boyan Balev ${ }^{4}$, Yana Bocheva ${ }^{5}$, Natalya Usheva ${ }^{6}$, \\ Ruzha Pancheva ${ }^{7}$ \\ ${ }^{1}$ Second Department of Internal Diseases, Faculty of Medicine, \\ Medical University of Varna \\ ${ }^{2}$ Department of Paediatrics, Faculty of Medicine, Medical University of Varna \\ ${ }^{3}$ First Department of Internal Diseases, Faculty of Medicine, Medical University of Varna \\ ${ }^{4}$ Department of Diagnostic Imaging, Faculty of Medicine, Medical University of Varna \\ ${ }^{5}$ Department of General Medicine and Clinical Laboratory, Faculty of Medicine, \\ Medical University of Varna \\ ${ }^{6}$ Department of Social Medicine and Health Care Organisation, Faculty of Public Health, \\ Medical University of Varna \\ ${ }^{7}$ Department of Hygiene and Epidemiology, Faculty of Public Health, \\ Medical University of Varna
}

\begin{abstract}
It is well-recognized that diabetes-related complications are the leading cause of the still increased morbidity and mortality from diabetes and exert a heavy economic burden on society. The discovery of insulin led to a dramatic change in life expectancy of patients with type 1 diabetes (T1D). Furthermore, it caused a major shift in the distribution of causes of death - from diabetic coma in the pre-insulin era, to long-term complications being the predominant causes of death nowadays. The aim of the present review is to assess the trends in the absolute and the relative mortality rates as well as the leading causes of death among patients with childhood-onset $(<18$ years) T1D in populations from different latitudes. It is also observed how disease duration, age at diagnosis, and year of diagnosis affect these mortality trends. Eight population-based studies published in English in the last 14 years, as well as another one, published in 2001, with different duration of follow-up, are included in the review. However, it is hard to compare different populations due to the dissimilarities in the study methods and the characteristics of the examined cohorts.
\end{abstract}

Keywords: childhood-onset type 1 diabetes, trends in mortality, causes of death

Address for correspondence:

Elitsa Hadzhieva

Faculty of Medicine

Medical University of Varna

55 Marin Drinov St

9002 Varna

e-mail:elihadjieva@yahoo.co.uk

Received: January 17, 2019

Accepted: March 8, 2019

\section{INTRODUCTION}

Type 1 diabetes (T1D) is the most common endocrine disorder and represents one of the most frequent chronic diseases in children. Major studies have shown a significant decrease in mortality after the implementation of insulin therapy $(1,2)$. In the Joslin Clinic in the United States, for example, mortality rates have declined substantially for patients aged between 10 and 30 years - from 360-824/1000 
person-years in 1897-1914 to $1.0-14.4 / 1000$ in 19501961 (1). However, T1D is still associated with considerable premature mortality (3-8).

The geographic differences in mortality among patients with childhood-onset T1D are well-recognized (8-11). The Diabetes Epidemiology Research International (DERI) mortality study shows the highest mortality rate in Japan despite the lowest incidence of T1D there (12). According to another large study, mortality rates are the highest in Japan, Russia, and Eastern Europe, while individuals in Bulgaria are 10 times more likely to die than those in Norway prior to the age of 25 years (13).

In contrast to earlier years, when the leading cause of death was diabetic ketoacidosis (DKA), long-term complications and particularly cardiovascular and renal disease, are the predominant causes of mortality in T1D nowadays (14). Nevertheless, high levels of excess mortality are also observed in subjects with short duration of the disease without signs of chronic complications (15-19). Early mortality is mainly associated with the development of DKA and severe hypoglycemia $(7,8,20)$. On the other hand, the EURODIAB study reveals that only $35 \%$ of deaths in children diagnosed after 1989 and followed up for 7.6 years are due to acute diabetes complications, while another $53 \%$ of deaths are due to non-diabetes causes (accidents, suicide, etc.) (7). It is worth noting that, sudden death during sleep is among the frequent causes of early mortality in some countries $(8,19,21,22)$.

The aim of the present review is to assess mortality trends in subjects with childhood-onset T1D and to make comparisons with the general population. Altogether, nine population-based studies are included. Five of them are long-term ( $\geq 14$-year follow-up), respectively those from Finland (5), Norway (8), USA $(9,14)$, and Japan (10). The cohort from Israel (23) has a mean duration of follow-up of $14 \pm 8$ years. The T1D subjects in Allegheny County (Pennsylvania) are used as representative of the T1D population in the USA $(9,14)$. The studies from Sweden (24), Wales (25), and Northern Ireland (26) are with a shorter mean duration of follow-up - between 8 and 12 years. The characteristics of the included studies are given in Table 1.

\section{Absolute and Relative Mortality}

Mortality is found to be similar in two of the countries with the highest incidence of T1D, Finland and Sweden (27) - 2.45/1000 and 2.2/1000 person-years for those diagnosed in 1970-1999 in Finland and in 1973-1982 in Norway, respectively $(5,8)$. The duration of follow-up for both cohorts is more than 20 years. Kenet et al. report lower rates of mortality in their study from Israel $(1.55 / 1000)$ including T1D subjects with a similar year of diagnosis to that of the cohorts from Finland and Norway (1965-1993) (23). Significantly higher mortality rates (more than

Table 1. Characteristics of the population-based studies

\begin{tabular}{lc|c|c|cc} 
& $\begin{array}{c}\text { Number of } \\
\text { Diseased }\end{array}$ & $\begin{array}{c}\text { Age at } \\
\text { Diagnosis }\end{array}$ & $\begin{array}{c}\text { Year of } \\
\text { Diagnosis }\end{array}$ & $\begin{array}{c}\text { Mean Duration } \\
\text { of Follow-Up } \\
\text { (Years) }\end{array}$ & $\begin{array}{c}\text { Final Year of } \\
\text { Survey }\end{array}$ \\
$\begin{array}{l}\text { USA/Allegheny } \\
\text { County }\end{array}$ & 1075 & $<18 \mathrm{yrs}$ & $1965-1979$ & $32 \pm 7.6$ & 2008 \\
Finland & 10492 & $0-14 \mathrm{yrs}$ & $1970-1999$ & 21.4 & 2007 \\
Sweden & 10200 & $0-14 \mathrm{yrs}$ & $1977-2000$ & 8 & not applicable \\
Norway & 1906 & $0-14 \mathrm{yrs}$ & $1973-1982$ & 24.2 & 2002 \\
Japan & 1385 & $<18 \mathrm{yrs}$ & $1965-1979$ & $24.4 \pm 6.4$ & 2005 \\
Northern Ireland & 3129 & $<15 \mathrm{yrs}$ & $1989-2012$ & 12.1 & 2012 \\
Wales & 3642 & $<15 \mathrm{yrs}$ & $1981-2015$ & 11.8 & 2015 \\
Israel & 1861 & $<17 \mathrm{yrs}$ & $1965-1993$ & $14 \pm 8$ & 1996 \\
\hline
\end{tabular}


6/1000) are observed among the T1D patients diagnosed from 1965 through 1979 in Allegheny County and Japan, and followed up until 2008 in the USA and 2005 in Japan, respectively $(9,10)$.

The absolute mortality is found to be higher among males in all of the long-term studies, except for that from the USA $(5,8-10)$. On the other hand, the relative mortality, represented by the standardized mortality ratio (SMR), is female-dominated, only in Norway it is similar in both sexes $(5,8-10)$. No difference in the mortality rate between sexes is observed in the cohort from Israel and no data exists regarding the relative mortality in the same population (23). Especially high is the overall SMR in Japan - 10.7, and that in Allegheny County is $6.9(9,10)$. The relative mortality is found to be lower in Norway, Finland, and Israel - overall SMR 4, 3.6, and 2.98, respectively $(8,5,23)$.

Lower all-cause mortality is observed in two short-term studies from Wales and Northern Ireland (subjects followed until 2015 and 2012, respectively) - 0.7/1000 in Wales and 1.5/1000 in Northern Ireland $(25,26)$. It is found to exceed almost 3 times the mortality rate of the general population (overall SMR 2.91 and 2.96 in Wales and Northern Ireland, respectively). The SMR is again female-dominated, while the absolute mortality is shown to be higher in males in Wales and similar for both sexes in Northern Ireland. The mortality registered by Dahlquist et al. in Sweden (the country with the second highest incidence of T1D in the world) is $0.96 / 1000$ for the subjects diagnosed between 1977 and 2000 and followed up for a mean time of 8 years (24). Similar to most of the other studies, the SMR of 2.15 is significantly higher in females $(\mathrm{p}=0.045)$, but it is lower compared with the SMR in the rest of the Scandinavian countries $(24,5,8)$. However, the follow-up period of the T1D subjects in this study is substantially shorter.

It is noteworthy that the mortality is especially high in Japan, as mentioned above, a country with one of the lowest incidences of T1D in the world (more than 20 times lower than that in Finland) (28). The first report of the DERI observational study in 1991 demonstrated that Japanese patients with T1D had a much worse prognosis than did similar patients in Finland, the USA, and Israel, with the most frequent causes of death being the acute complica- tions of diabetes and end-stage renal disease (ESRD) (29-31). A possible reason discussed for the higher mortality rate in Japan is the low incidence of T1D itself in this country, which probably causes difficulties in the diagnosis and treatment of the disease. On the other hand, the EURODIAB study shows no significant relationship of mortality with the country's incidence rate or gross domestic product (7).

Much higher is also the number of deaths in the cohort from the USA in comparison with the European countries from the population-based studies included. The significant impact of the disease on the overall mortality is demonstrated by the high SMR of 6.9, compared with the European countries, where the SMR varies between 2 and 4 (9,5,8,24-26). These geographical differences could be due to the high-cost healthcare in the USA, which is probably an obstacle for a frequent contact of some patients with a physician. Another possible reason could be the higher mortality rate in African Americans (a part of the population in Allegheny County) $(9,14)$.

Time Trends in Mortality (Impact of Year of Diagnosis on Mortality)

The influence of calendar year of diagnosis on mortality is examined in the population-based studies from Norway, Finland, Japan, and the USA. No significant difference in cumulative survival is found in Norway when the cases diagnosed between 1978 and 1982 are compared over 20 years of disease duration with those diagnosed between 1973 and 1977 (0.96 vs $0.97, \mathrm{p}=0.52$ ) (8). Another population-based Norwegian study including childhood-onset T1D subjects diagnosed in 1973-1982 and 1989-2012, and followed up until 2013, shows more contemporary data (32). Temporal trends in mortality assessed by cox regression analysis show that it decreased significantly by $49 \%$ (HR $0.51,95 \%$ CI $0.28-0.93$; $\mathrm{p}=0.03$ ) for those diagnosed in 1999-2012 compared with subjects diagnosed in 1973-1982. However, the followup time of both groups is different. Improved survival of patients with later calendar year of diagnosis is also observed by Harjutsalo et al. in Finland (5). The 20 -year cumulative mortality in the groups of patients diagnosed in 1970-1974, 1975-1979, 1980-1984, and $1985-1989$ is $4.7 \%$ (3.7\% to $5.8 \%$ ), $4.3 \%$ (3.3\% to $5.2 \%), 3.6 \%$ (2.8\% to $4.5 \%$ ), and $2.7 \%$ (1.9\% to $3.4 \%)$, respectively. However, the follow-up time of the last 
group has not yet reached 20 years. In the same cohort, SMR decreases by $4.3 \%$ per year of diagnosis, after adjustment for duration and age at onset of diabetes. Furthermore, an improvement in mortality due to chronic complications is observed - a significant decline from 10.0 (5.8 to 13.1)/10 000 in patients diagnosed in 1970-1974 to 2.2 (0.9 to 4.5$) / 10000$ in those diagnosed in 1985-1989 ( $\mathrm{p}<0.001)$. On the other hand, mortality due to acute complications (nonalcohol related) shows a non-significant tendency to increase from 2.1 ( 0.8 to 4.6 )/10 000 to 4.1 (1.9 to 6.5)/10 000 .

Noticeable is the improvement in T1D mortality in Japan. The 15-year survival increases from $87.6 \%$ for the subjects diagnosed in $1965-1969$ to $96 \%$ for those diagnosed in 1975-1979 (33). This beneficial influence of the calendar year of diagnosis is preserved even for longer period of follow-up. SMR observed at the 25th year of follow-up declines from 19.3 in the 1965-1969 diagnosis group to 6.6 in the 1975-1979 diagnosis group (10). Improvement in patient prognosis is also observed in the representative cohort from the USA with T1D onset after 19651969. Significantly higher mortality rates from diabetes-related causes are registered for the 1965-1969 cohort in comparison with the 1975-1979 cohort (RR $1.5, \mathrm{p}=0.05)$. In addition, further analysis by diabetes duration reveals that the 1975-1979 cohort has a significantly lower mortality rate compared with the 1965-1969 diagnosis group over the first 20 years of disease duration (RR 0.45, $\mathrm{p}=0.01$ ) (14).

Unlike Finland and the USA, where overall mortality rates continue to rise, as would be expected with increasing age and T1D duration, in Japan the overall mortality rates decline with longer period of follow-up $(11,34)$. This is further an indicator of the dramatic improvements in T1D care in Japan after 1980.

\section{Effect of Age at Onset of T1D on Mortality}

Three of the long-term studies included in the present review assess the effect of age at diabetes onset on overall mortality. Skrivarhaug et al. find a significantly higher mortality rate in individuals with diabetes onset at age 10-14 years in Norway than in those with onset below 10 years of age $(2.85 / 1000$ vs 1.73/1000; RR 1.70, 95\% CI 1.15-2.51) (8). A similar tendency is observed in Finland and Japan regarding
T1D patients diagnosed in 1965-1979 and followed up until 1994 (2 of the cohorts in the DERI study, 11). It is found that the absolute mortality is almost two times higher in patients with diabetes onset at pubertal age ( $\geq 11$ years for girls, $\geq 12$ years for boys) than in those with diagnosis in prepubertal age $(9.41 / 1000$ vs $4.56 / 1000$ in Japan, $4.46 / 1000$ vs $2.78 / 1000$ in Finland). The effect of diagnosis in pubertal age is no longer significant after adjustment for mortality in the corresponding age groups of the general population. The SMR for pubertal and prepubertal age is 16.4 (12.7-20.9) and 10.8 (8.4-13.6) in Japan, and 3.7 (3.2-4.3) and 3.6 (3.1-4.3) in Finland, respectively. This is an expression of the higher mortality in pubertal age in the general population as well.

Laron-Kenet et al. find no relationship between overall T1D mortality in Israel and age at diagnosis (under and over 12 years). However, the death of the patients diagnosed before 12 years of age occurred at a younger age than those diagnosed at 12 years or later (log-rank 5.8; $\mathrm{p}=0.016)$ (23). An effect of age at diagnosis on absolute mortality is also observed in the short-term study from Wales - higher mortality risk for those diagnosed in teenage years than those who developed T1D younger (OR per additional year of age 1.16 (1.05-1.28); $\mathrm{p}=0.005)$ (25).

\section{Causes of Death}

When studying the causes of death among T1D subjects in the long-term studies observed, the violent death (accidents, suicides, intoxications) appears to be the most common in the cohorts from Norway and Finland (for the diagnosed in 1970-1989 in Finland), accounting for around $30 \%$ of all death cases $(5,8)$. They are followed by acute $(22.6 \%)$ and chronic diabetes complications (28.7\%) in Finland, and acute complications (22.3\%), sudden death (16.5\%), and cardiovascular (CV) death (14.6\%) in Norway. On the other hand, in the study from Israel, which is with a significantly shorter observational time, the leading mortality causes are DKA (21.6\%), infections (21.6\%), and chronic diabetes complications (24.3\%) (23). The most common cause of death in the cohort from Allegheny County is CV mortality (36.2\%), followed by acute metabolic complications (16.13\%), infections (16\%) and renal diseases (13.26\%) (14). Most frequent for the Japanese population is the mortality due to ESRD (22.87\%), followed by CV mortali- 
Elitsa Hadzhieva, Mila Boyadzhieva, Violeta Iotova et al.

ty (17.94\%), acute metabolic complications (17.04\%), and infections (15.25\%) (10).

Scrivarhaug et al. analyze the causes of death in T1D subjects in Norway according to age at death (8). They find acute metabolic complications (38\%) and violent death $(23 \%)$ to be the most common causes before the age of 20 years. The same two remain most frequent ( $28 \%$ and $33 \%$, respectively) among subjects aged 20-30 years, while after the age of 30 years CV death is predominant (30\%). The impact of disease duration on the causes of death has been studied in the same population. Dominant in the first 10 years of T1D are acute metabolic complications (42\%), while after that - violent death (29\%). Acute metabolic complications (22\%) turn out to be the second most common cause of death after 10-19 years and CV diseases (26\%) - after 20 years of diabetes duration. The influence of disease duration on the leading causes of death in T1D subjects is also assessed in the USA, Allegheny County, by Secrest et al. (14). Within the first 10 years of diabetes onset, $>70 \%$ of all deaths are due to acute diabetes complications, while after 10 years of diabetes, the same become a minor but persistent (9-15\%) cause of death in this population. On the other hand, after 10 years of diabetes, CV mortality becomes the leading cause of death, eventually accounting for $40 \%$ of all deaths after 20 years of duration. Renal disease does not contribute to any deaths until after 10 years of diabetes duration, when it contributes to about half of all deaths in the same cohort. Similar to the other population-based studies, acute diabetes complications are the most common cause of early mortality also in Japan (40\% of the death cases followed for less than 10 years), while mortality due to ESRD dominates in the subjects with a longer follow-up time (10-19 years) (10). The percentage of $\mathrm{CV}$ death also increases with longer duration of T1D, becoming the leading mortality cause after 3035 years of observation.

A comparison between the causes of death among T1D subjects and the general population in Norway demonstrates about 20 -fold higher mortality rates for ischemic heart disease (IHD) and cerebrovascular disease for the patients with T1D, while SMR for violent death is significantly lower (3.3 for men, 1.7 for women) (8). ESRD is responsible for a small number $(8 \%)$ of all deaths in the same study. Nevertheless, SMR is especially high for this cause -
220 for males and 155 for females. In Finland, SMR for IHD is high, while that for cerebrovascular disease is significantly lower (17.4 and 5.1, respectively) (5). In Finland and Norway, the mortality from suicide is not significantly greater in patients with diabetes compared with the general population $(5,8)$. However, it accounts for 10-20\% of all deaths.

Similar are also the observations for the diabetic populations in Allegheny County (USA) and Japan - high SMR for CV diseases and renal diseases, but also for infections $(14,10)$. On the other hand, deaths from non-diabetes-related causes occur at similar rates in T1D to the age-, sex-, and racematched general population (SMR for accidents/suicides and neoplasms - 1.2 in the USA, 2.1 and 0.5 in Japan, respectively).

DKA is the leading diabetes-related cause of death in the short-term studies from Wales, Northern Ireland, and Sweden (24-26). On the other hand, the chronic diabetes complications are responsible for a small percentage of mortality in these cohorts, which is most probably a result of the shorter followup time and the relatively young age of the patients. It is worth noting that the so called dead-in-bed syndrome is the second most common cause of death among diabetic subjects in Sweden, comprising 22\% of all deaths in this cohort (24).

\section{CONCLUSION}

In conclusion, childhood-onset T1D is still associated with premature mortality even in societies with well-organized health care systems and unrestricted access to treatment of diabetes and its complications. Higher is the absolute mortality among males in the majority of the population-based studies included in the review. On the other hand, the relative mortality is female-dominated in almost all the cohorts, thus demonstrating that diabetes greatly attenuates, or may even reverse, the protective effect of female sex. Especially high is the mortality rate in Japan and the USA, unlike, for example, the Scandinavian countries, where the incidence of T1D is the highest. On the other hand, the dissimilarities in the study methods and the characteristics of the examined cohorts (including the longer period of followup for the Allegheny County population) make comparisons difficult. There are common trends for longer survival with later calendar year of diagnosis and 
for higher mortality with pubertal (compared with prepubertal) onset of disease in most of the long-term studies. The leading causes of death among T1D subjects appear to be the acute and chronic diabetes complications. However, in some cohorts a large number of death cases are also due to violent death, including suicides and intoxications. That should focus the attention on the psychological health of childhood-onset $\mathrm{T} 1 \mathrm{D}$ as well. The worldwide increase in incidence of the disease, as well as the continuous technological progress in diabetology, raise the importance of conducting long-term contemporary mortality studies in order to establish the efficacy of T1D treatment over time.

The study is supported by a grant 13/3 from 14.12.2017 from the Scientific Research Fund at the Ministry of Education and Science of Bulgaria and the Science Fund of the Medical University of Varna.

\section{REFERENCES}

1. Marks HH. Longevity and mortality of diabetics. Am J Public Health Nations Health. 1965; 55:41623. doi: 10.2105/ajph.55.3.416.

2. Westlund K. Incidence of diabetes mellitus in Oslo, Norway 1925 to 1954, Report No. 11 of the life insurance companies' institute for medical statistics at the Oslo city hospitals. Brit J Prev Soc Med. 1966; 20(3):105-16.

3. Morgan CL, Currie CJ, Peters JR. Relationship between diabetes and mortality: a population study using record linkage. Diabetes Care. 2000; 23(8):1103-7.

4. Arias E, Anderson RN, Hsiang-Ching K, Murphy SL, Kochanek KD. Deaths: final data for 2001. Natl Vital Stat Rep. 2003; 52(3): 1-115.

5. Harjutsalo V, Forsblom C, Groop PH. Time trends in mortality in patients with type 1 diabetes: nationwide population based cohort study. BMJ. 2011; 343:d5364. doi: 10.1136/bmj.d5364.

6. Groop PH, Thomas MC, Moran JL, Waden J, Thorn LM, Makinen VP, et al. The presence and severity of chronic kidney disease predicts all-cause mortality in type 1 diabetes. Diabetes. 2009; 58(7): 1651-8. doi: 10.2337/db08-1543.

7. Patterson CC, Dahlquist G, Harjutsalo V, Joner G, Feltbower RG, Svensson J, et al. Early mortality in EURODIAB population-based cohorts of type 1 diabetes diagnosed in childhood since 1989. Diabetologia. 2007; 50(12):2439-42. doi: 10.1007/ s00125-007-0824-8.

8. Skrivarhaug T, Bangstad HJ, Stene LC, Sandvik L, Hanssen KF, Joner G. Long-term mortality in a nationwide cohort of childhood-onset type 1 diabetic patients in Norway. Diabetologia. 2006; 49(2):298-305. doi: 10.1007/s00125-005-0082-6.

9. Secrest AM, Becker DJ, Kelsey SF, LaPorte RE, Orchard TJ. All-cause mortality trends in a large population based cohort with long-standing childhood-onset type 1 diabetes. The Allegheny County type 1 diabetes registry. Diabetes Care. 2010; 33(12):2573-9. doi: 10.2337/dc10-1170.

10. Morimoto A, Onda $Y$, Nishimura R, Sano H, Utsunomiya K, Tajima N. Cause-specific mortality trends in a nationwide population-based cohort of childhood-onset type 1 diabetes in Japan during 35 years of follow-up: The DERI Mortality study. Diabetologia. 2013; 56(10):2171-5.

11. Asao K, Sarti C, Forsen T, Hyttinen V, Nishimura $\mathrm{R}$, Matsushima $\mathrm{M}$, et al. Long-term mortality in nationwide cohorts of childhood-onset type 1 diabetes in Japan and Finland. Diabetes Care. 2003; 26(7):2037-42. doi: 10.2337/diacare.26.7.2037.

12. International evaluation of cause-specific mortality and IDDM. Diabetes Epidemiology Research International Mortality Study Group. Diabetes Care. 1991; 14(1): 55-60.

13. Matsushima $M$, Laporte RE, Maruyama $M$, Shimizu K, Nishimura R, Tajima N. Geographic variation in mortality among individuals with youth-onset diabetes mellitus across the world. DERI Mortality Study Group. Diabetes Epidemiology Research International. Diabetologia. 1997; 40(2): 212-6.

14. Secrest AM, Becker DJ, Kelsey SF, LaPorte RE, Orchard TJ. Cause-specific mortality trends in a large population-based cohort with long-standing childhood-onset type 1 diabetes. Diabetes. 2010; 59(12): 3216-22.

15. Sex differences in the mortality associated with insulin-dependent diabetes mellitus in four countries: the Diabetes Epidemiology Research International (DERI) Study. Am J Epidemiol. 1991; 133(6):577-84.

16. Joner G, Patrick $S$. The mortality of children with type 1 (insulin-dependent) diabetes mellitus in 
Elitsa Hadzhieva, Mila Boyadzhieva, Violeta Iotova et al.

Norway, 1973-1988. Diabetologia. 1991; 34(1):29

-32. doi: 10.1007/bf00404021.

17. Sartor G, Dahlquist G. Short-term mortality in childhood onset insulin-dependent diabetes mellitus: a high frequency of unexpected deaths in bed. Diabet Med. 1995; 12(7):607-11. doi: 10.1111/ j.1464-5491.1995.tb00550.x.

18. Podar T, Solntsev A, Reunanen A, Urbonaite B, Zalinkevicius R, Karvonen M, et al. Mortality in patients with childhood-onset type 1 diabetes in Finland, Estonia, and Lithuania: follow-up of nationwide cohorts. Diabetes Care. 2000; 23(3):290-4. doi: 10.2337/diacare.23.3.290.

19. Dahlquist G1, Källén B. Mortality in childhoodonset type 1 diabetes: a population-based study. Diabetes Care. 2005; 28(10): 2384-7. doi: 10.2337/ diacare.28.10.2384.

20. Laing SP, Swerdlow AJ, Slater SD, Botha JL, Burden AC, Waugh NR, et al. The British Diabetic Association Cohort Study, II: cause-specific mortality in patients with insulin-treated diabetes mellitus. Diabet Med. 1999; 16(6): 466-71. doi: 10.1046/j.1464-5491.1999.00076.x.

21. Tattersall RB, Gill GV. Unexplained deaths of type 1 diabetic patients. Diabet Med. 1991;8(1):49-58. doi: 10.1111/j.1464-5491.1991.tb01516.x.

22. Sovik O, Thordarson H. Dead-in-bed syndrome in young diabetic patients. Diabetes Care. 1999; 22(2): B40- 2.

23. Laron-Kenet T, Shamis I, Weitzman S, Rosen S, Laron ZV. Mortality of patients with childhood onset (0-17 years) Type I diabetes in Israel: a population-based study. Diabetologia. 2001; 44 (3):B81-6. doi: 10.1007/pl00002959.

24. Dahlquist G, Källén B. Mortality in childhoodonset type 1 diabetes: a population-based study. Diabetes Care. 2005; 28(10):2384-7. doi: 10.2337/ diacare.28.10.2384.

25. Wasag DR, Gregory JW, Dayan C, Harvey JN; Brecon Group. Excess all-cause mortality before age 30 in childhood onset type 1 diabetes: data from the Brecon Group cohort in Wales. Arch Dis Child. 2018; 103(1):44-8. doi: 10.1136/ archdischild-2016-312581.

26. Morgan E, Black CR, Abid N, Cardwell CR, McCance DR, Patterson CC. Mortality in type 1 diabetes diagnosed in childhood in Northern Ireland during 1989-2012: A population-based cohort study. Pediatr Diabetes. 2018; 19(1):166-70. doi: $10.1111 /$ pedi.12539.

27. Soltesz G, Dahlquist GG. Global trends in childhood type 1 diabetes. Diabetes Atlas. 3rd ed; 2012. pp. 154-8.

28. International Diabetes Federation (2011) IDF diabetes atlas, 5 th ed. International Diabetes Federation, Brussels, Belgium.

29. Major cross-country differences in risk of dying for people with IDDM. Diabetes Epidemiology Research International Mortality Study Group. Diabetes Care. 1991; 14(1):49-54.

30. International evaluation of cause-specific mortality and IDDM. Diabetes Epidemiology Research International Mortality Study Group. Diabetes Care 1991; 14 (1): 55-60.

31. Matsushima M, Tajima N, Laporte RE, Orchard TJ, Tull ES, Gower IF, et al. The Diabetes Epidemiology Research International (DERI) U.S.-Japan Mortality Study Group: Markedly increased renal disease mortality and incidence of renal replacement therapy among IDDM patients in Japan in contrast to Allegheny County, Pennsylvania, USA. Diabetologia 1995; 38(2):23643. doi: 10.1007/bf00400100.

32. Gagnum V. Mortality, causes of death and endstage renal disease in type 1 diabetes. Dissertation submitted for the degree of $\mathrm{PhD}, 2016$. Institute of Clinical Medicine, Faculty of Medicine, University of Oslo. Division of Paediatric and Adolescent Medicine, Oslo University Hospital. Oslo Diabetes Research Centre.

33. Nishimura R, Matsushima M, Tajima N, Agata T, Shimizu H. Diabetes Epidemiology Research International Study Group: A major improvement in the prognosis of individuals with IDDM in the past 30 years in Japan. Diabetes Care. 1996; 19(7):758- 60. doi: 10.2337/diacare.19.7.758.

34. Secrest AM. Mortality trends in a population-based type 1 diabetes cohort. Dissertation, University of Pittsburgh. Ann Arbor, MI: ProQuest/UMI, 2010. Publication No. AAT 3435523. 